\title{
Radiology-Pathology Correlations of Intracranial Clots: Current Theories, Clinical Applications, and Future Directions
}

\author{
(D).C. Benson, DD.F. Kallmes, (D) A.S. Larson, and (D). Brinjikji
}

\begin{abstract}
SUMMARY: In recent years, there has been substantial progression in the field of stroke clot/thrombus imaging. Thrombus imaging aims to deduce the histologic composition of the clot through evaluation of various imaging characteristics. If the histology of a thrombus can be reliably determined by noninvasive imaging methods, critical information may be extrapolated about its expected response to treatment and about the patient's clinical outcome. Crucially, as we move into an era of stroke therapy individualization, determination of the histologic composition of a clot may be able to guide precise and targeted therapeutic effort. Most radiologists, however, remain largely unfamiliar with the topic of clot imaging. This article will review the current literature regarding clot imaging, including its histologic backdrop, the correlation of images with cellular components and treatment responsiveness, and future expectations.
\end{abstract}

ABBREVIATIONS: MT = mechanical thrombectomy; HMCAS = hyperdense middle cerebral artery sign; NETs = neutrophil extracellular traps; RBC = red blood cell; SVS = susceptibility vessel sign; TAI = thrombus attenuation increase

$\mathrm{T}$ he introduction of mechanical thrombectomy (MT) heralded the beginning of a new era in stroke research, in which retrieved clot tissue was available for histologic analysis. As it turned out, there was substantial heterogeneity in the histologic and physical characteristics of retrieved thrombi. This observation led to widespread exploration into the treatment implications, etiologic origins, and prognostic indicators of clot subtypes. It also accelerated the interest in the subfield of radiology-pathology correlation, in which attempts were made to use various imaging modalities to determine the histologic makeup of clots.

Two main methods have been used to characterize the histology of clot on imaging: the attenuation value of a clot on NCCT and its perviousness. MR imaging, too, has been used, but to a lesser degree. "Perviousness" refers to the degree with which blood—and, consequently, contrast-is able to flow into and through a clot. A highly pervious clot intuitively represents a porous structure that might confer increased responsiveness to thrombolysis and mechanical thrombectomy procedures. However, the still-emerging

Received January 11, 2021; accepted after revision April 6. From the Department of Neuroradiology, Mayo Clinic, Rochester, Minnesota.

Funding was received by Waleed Brinjikji as part of a National Institutes of Health/ National Institute of Neurological Disorders and Stroke grant: 1R01NS105853.

Please address correspondence to John C. Benson, MD, Department of Radiology, Mayo Clinic, 200 1st St SW, Rochester, MN 55905; e-mail: Benson.john3@mayo.edu

- Indicates open access to non-subscribers at www.ajnr.org

Indicates article with online supplemental data.

http://dx.doi.org/10.3174/ajnr.A7249 field of clot perviousness imaging has been beset by inconclusive and, at times, contradictory data.

Nevertheless, the field of intracranial clot imaging holds promise for the future of individualization of stroke treatment. If the physical and histologic attributes of a clot can be inferred from its imaging characteristics, diagnostic imaging could allow early prognostication of various therapeutic efforts and could even be used to tailor specific pharmacologic and interventional therapies on the basis of clot subtypes. These substantial clinical implications have led to numerous scientific pursuits of perviousness imaging, particularly within the past few years. In this article, we will review the current literature on stroke clot imaging with a focus on both perviousness and radiology-pathology correlations.

\section{Clot Histologic and Physical Characteristics}

Clots are composed of 4 major components: red blood cells (RBCs), fibrin, platelets, and white blood cells. Substantial variability exists in the relative proportion of each component in various clots. The most commonly used terms to describe clot composition are RBC-rich/-poor, fibrin-rich/-poor, and platelet-rich/-poor (Fig 1). However, there is no standard definition for what makes a clot rich or poor in a given histologic component.

The histologic composition of a clot is used as a surrogate for its physical properties. RBC-rich thrombi are softer and more porous and have a lower static coefficient of friction; platelet-rich and fibrin-rich clots are harder and less porous and have a higher 

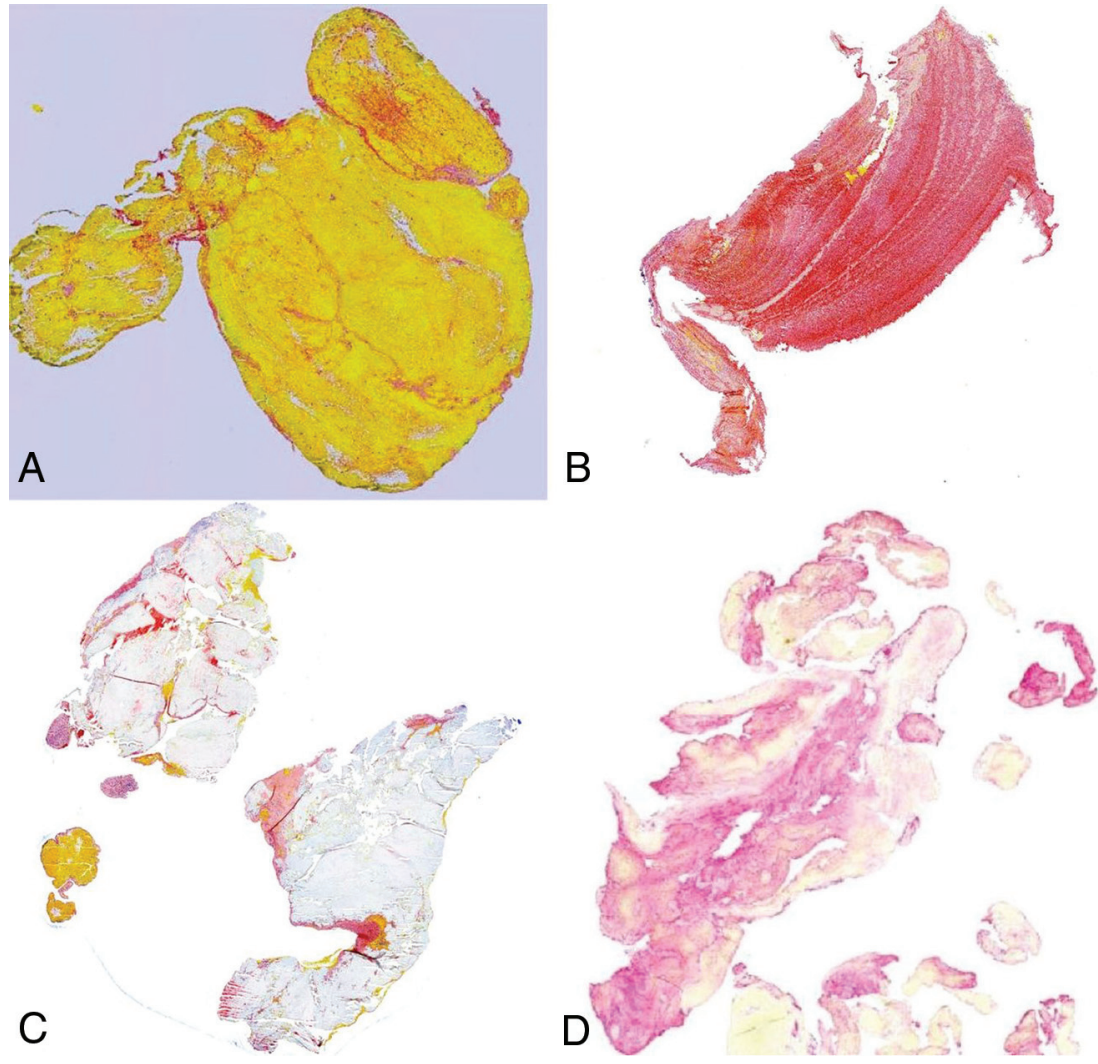

FIG 1. Histologic examples of various clot types. RBC-rich (A), fibrin-rich (B), platelet-rich (C) (all stained with Martius Scarlet Blue), and NET-rich (D) clots (immunohistochemistry using citrullinated $\mathrm{H} 3$ antibody) are shown, though standard definitions for these clot types have not yet been created.

static coefficient of friction. ${ }^{1}$ However, there have not been extensive experiments into the histologic perviousness of clots.

Histologic differences among clots have direct clinical implications, particularly with regard to the ease, or difficulty, with which such clots are treated with MT or thrombolysis. RBC-rich clots are more responsive to $\mathrm{PA}$ than fibrin-rich or platelet-rich clots. ${ }^{2,3}$ Fibrin-rich clots are also more difficult to remove during MT and require longer intervention times. Clots successfully retrieved with MT, meanwhile, exhibit higher RBC density. ${ }^{4,5}$

Different pathomechanisms have been offered to explain these differences. For example, fibrin-rich clots are more likely to embolize during MT, suggesting the greater fragility of such clots. ${ }^{6} \mathrm{RBC}$-rich clots are less stiff, thus allowing better integration of stent devices into the thrombi during extraction. ${ }^{7}$ In addition, the greater friction exhibited by fibrin-rich clots may make them harder to remove during MT. ${ }^{1,8}$ However, frictional differences also make RBC clots more prone to intraprocedural migration. ${ }^{9}$

\section{Perviousness Imaging}

As stated above, perviousness is the extent to which blood flows through a clot. Because arterially timed contrast serves as a proxy for arterial flow, CTA represents the most conceptually straightforward technique with which to demonstrate the perviousness of a clot. The use of CTA for perviousness imaging is also an enticing concept because it is nearly ubiquitous in stroke imaging. On CTA, perviousness is measured by comparing intraclot radiodensity units before and after the administration of arterial phase IV contrast (so-called thrombus attenuation increase [TAI]). Therefore, highly pervious clots would display substantial differences in attenuation before and after contrast infusion; impervious clots, conversely, would change minimally.

TAI is typically measured by aligning thin-section NCCT images to CTA images. ROIs are then measured along the course of the thrombus on both image sets. Subtracting the mean NCCT ROI value from the CTA ROI value yields the TAI (Fig 2). ${ }^{10}$ The method with which the TAI is determined has varied among studies. Some authors have used coregistration of NCCT and CTA to ensure measurement of the entire clot. Others, however, have simply drawn $\geq 1$ circular ROI within the clot segment, thereby resulting in a less precise measurement. ${ }^{10}$ Definitions of "perviousness" have also varied (Online Supplemental Data).

For both TAI and NCCT attenuation measurements, care must be taken when dealing with highly calcified thrombi because of both the substantial impact of calcifications on attenuation values and the associated streak and partial volume artifacts. Thus, calcified thrombi are often excluded from analyses. ${ }^{11}$

The use of multiphase CTA offers some potential advantages for clot perviousness imaging. Mostly, it solves the conundrum of suboptimal timing-that is, perviousness cannot be determined on CTA if the arterial phase contrast has not yet reached the thrombus in question. The additional acquisition of both venousand delayed-phase images on multiphase CTA ensures the arrival of contrast to or through the thrombus during at least some time point. To date, however, evidence supporting the conceptual benefit of multiphase CTA in perviousness analysis remains sparse. Santos et $\mathrm{al},{ }^{12}$ for example, found that venous and delayed-phase images had poorer associations with outcome than those obtained in the arterial phase. Chen et $\mathrm{al}^{13}$ used a more robust version of dynamic CTA, in which 26 phases were acquired as part of a CTP protocol. In doing so, the authors found that this method more successfully offset the contrast-timing issue: The maximum TAI was better associated with outcome than the standard arterial phase. Nevertheless, neither study assessed correlations between multiphase perviousness markers and the histologic composition of retrieved clots. Future studies will be needed to provide more direct evidence of the correlation between clot perviousness and findings on multiphase CTA and CTP. 


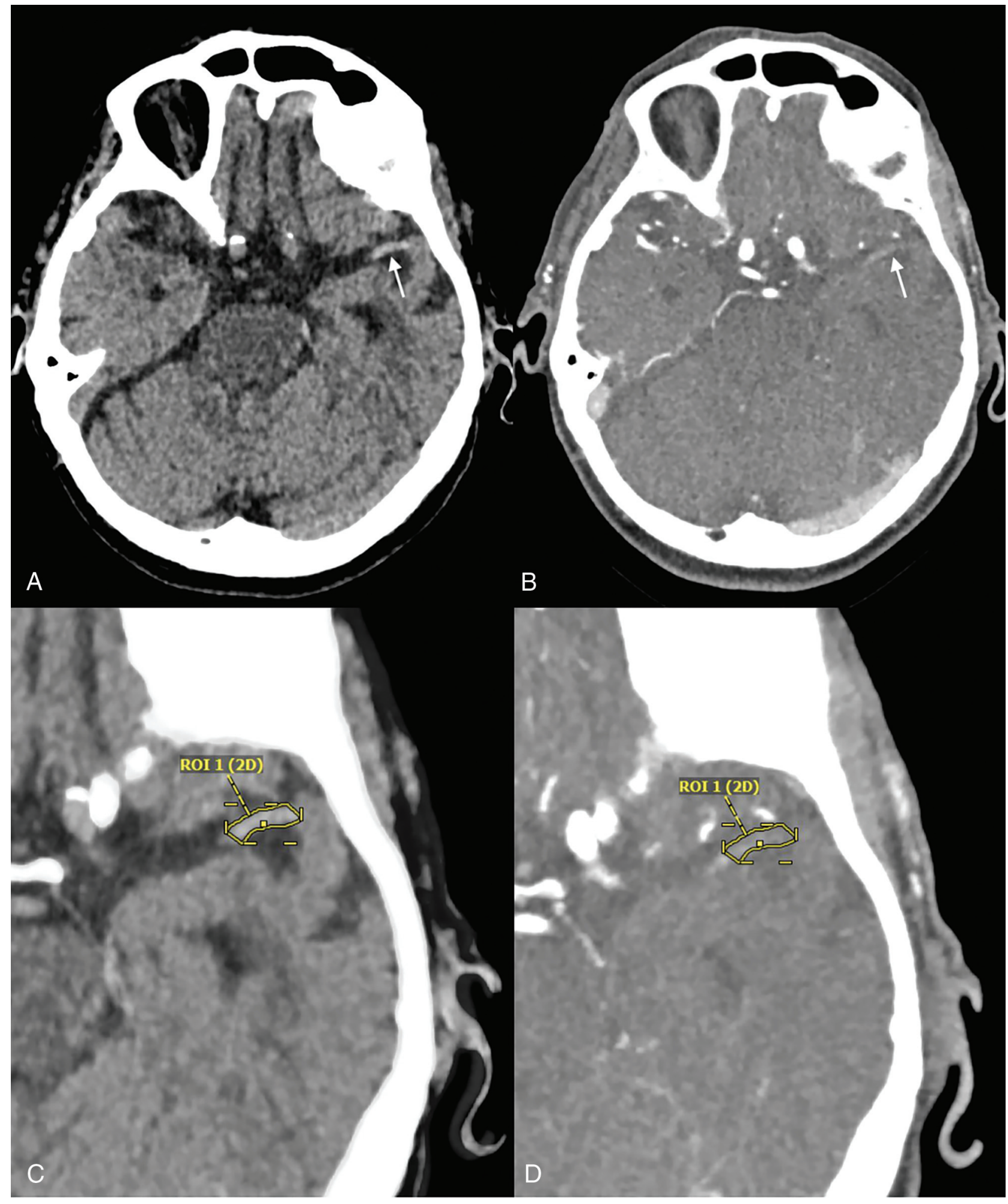

FIG 2. Measurement of clot perviousness on CT using TAI. NCCT (A) demonstrates a hyperdense vessel sign in the distal left Ml (arrow), with faint attenuation in this region also seen on CTA (arrow, B). Comparison of intraclot attenuation between the NCCT (C) and CTA (D) yields a $23 \%$ increase in Hounsfield units following contrast administration.

\section{Histologic Correlations}

On NCCT, the most common methods of clot assessment are by absolute attenuation, relative attenuation, and the presence or absence of a hyperdense middle cerebral artery sign (HMCAS).
Absolute attenuation is determined by measuring an intraclot ROI along the course of the thrombus. ${ }^{10}$ Relative attenuation is determined by comparing this calculation with similar measurements performed on the contralateral artery. ${ }^{11}$ A relative measurement 


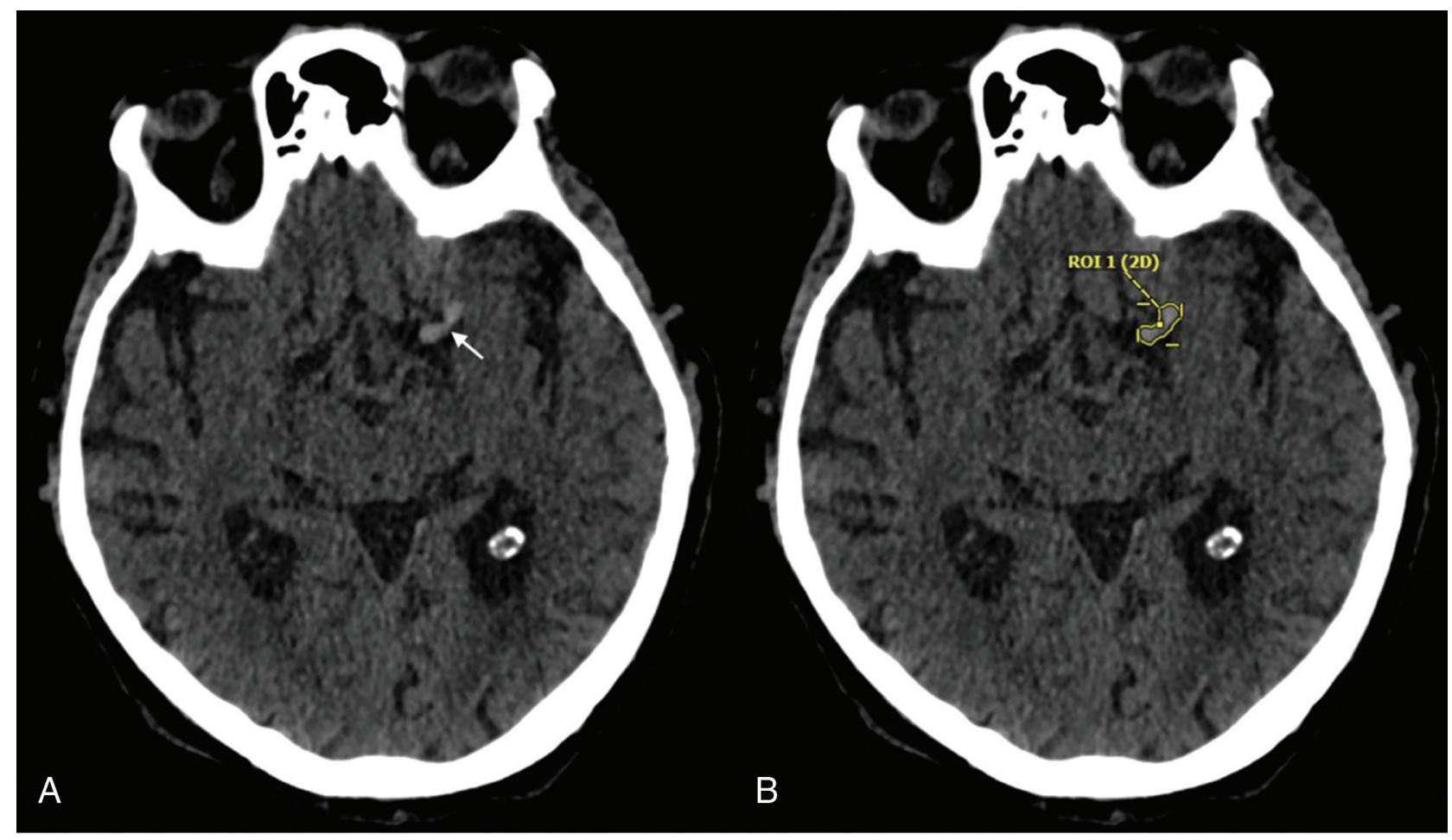

FIG 3. Intracranial clot evaluation on NCCT. Both the subjective presence of a hyperdense MCA sign (arrow in A) and objective measurement of intraclot attenuation $(B)$ are predictive the histologic composition of a clot and responsiveness to treatment. Relative attenuation, in which the involved artery is compared with the contralateral side, may also be used (not shown).

may be useful because it corrects for underlying issues that might affect attenuation values, such as hematocrit or scanner differences (Fig 3). ${ }^{14}$ Generally, thin-section $(\leq 2.5 \mathrm{~mm})$ imaging is suggested for intraclot attenuation measurements. ${ }^{15,16}$ An HMCAS, conversely, is based on the subjective identification of an artery with pathologically hyperdense attenuation. MIP images are particularly useful to improve detection of HMCASs. ${ }^{17}$

Lower Hounsfield units are associated with fibrin- and/or platelet-rich clots, while higher Hounsfield units are associated with RBC-rich clots. ${ }^{2,6,7,18-20}$ The reported density of so-called RBC-rich clots has varied widely among reports, likely related to differences in CT scanning parameters and definitions of clot composition. Maekawa et $\mathrm{al}^{21}{ }^{21}$ for example, found the density of erythrocyte-rich clots to be $48.1 \mathrm{HU}$, compared with $32.1 \mathrm{HU}$ in their fibrin-rich counterparts. Liebeskind et al, ${ }^{22}$ conversely, based their results on a subjective analysis of the presence or absence of an HMCAS, though they did report the mean density of clots having the HMCAS as $61 \mathrm{HU}$. Clot types were shown to be more accurately differentiated on dual-energy CT on an in vitro study, though this is yet to be validated with an in vivo cohort. ${ }^{21}$

On CTA, despite the theoretic ease with which the technique could be used to determine clot perviousness, conclusions from multiple prior attempts at histologic correlation have been frustratingly inconsistent. In the first major study to compare perviousness on CTA with histology, Berndt et $\mathrm{al}^{23}$ found that pervious clots have greater fibrin/platelet conglomerations and less RBC fractions. Benson et $\mathrm{al}^{24}$ subsequently found that pervious clots (defined as an increase in the intrathrombus Hounsfield unit of $\geq 10$ on CTA compared with NCCT) were more likely to be RBC-rich, while impervious clots were more likely to be fibrinand white blood cell-rich. Most recently, Patel et al, ${ }^{5}$ using a cohort of 40 patients treated with MT, found that perviousness was associated with higher clot histologic percentages of both fibrin/platelet aggregates and was negatively correlated with the percentage of RBCs.

The reason for these contradictory results is befuddling. The superior therapeutic responses in both RBC-rich clots and pervious clots would seem to indicate that pervious clots would demonstrate erythrocyte-laden histology. However, there are several possible explanations for the observed differences. As Patel et $\mathrm{al}^{5}$ noted, inconsistencies in statistical methodology could have contributed to the variability in outcomes in these studies. The time between imaging and clot retrieval may also have played a role. Cines et $\mathrm{al}^{25}$ found that clots undergo a natural contraction with time, and this type of histopathologic evolution could potentially have impacted the results. Next, there is some intrinsic bias in studies based solely on histologic analysis of successfully retrieved clots without any sort of postmortem analysis. Finally, the variability in results also raises the possibility that the observed differences were related to histologic markers that were not specifically assessed such as neutrophil extracellular traps (NETs) and the von Willebrand factor. Put more simply, is perviousness on imaging "seeing" markers of treatment response that we have not yet histologically determined?

On MR imaging, correlations between imaging findings and the histologic composition of clots remain relatively unknown. However, the so-called susceptibility vessel sign (SVS), a linear intravascular focus of hypointense signal on SWI, is highly 
Summary of the most commonly used methods for determining clot histology and predicted treatment response on NCCT, CTA, and MR imaging ${ }^{\mathrm{a}}$

\begin{tabular}{lccc}
\hline & Measurement Method & Histologic Correlation & Favorable Therapeutic Response \\
\hline NCCT & HU & $\uparrow \mathrm{HU}=\uparrow \mathrm{RBC}, \downarrow$ fibrin/platelets & $\uparrow \mathrm{HU}$ \\
CTA & TAI & Conflicting data & $\uparrow \mathrm{TAl}$ \\
MR imaging & SVS & SVS $=\uparrow \mathrm{RBC}, \downarrow$ fibrin/platelets & + SVS \\
\hline
\end{tabular}

Note:-HU indicates Hounsfield unit.

${ }^{a}$ Up and down arrows denote greater or lesser values (HU or TAI) and relative histologic composition. The plus sign denotes the presence of an imaging sign (ie, SVS).

specific for occlusive arterial thrombus. ${ }^{26}$ Clots that demonstrate an SVS have been shown to be richer in RBC composition, thought to be related to the paramagnetic properties of deoxygenated hemoglobin. ${ }^{27}$ Similar results have also been reported using gradient-echo sequences. $^{22,28}$

\section{Treatment Response}

Multiple studies have shown that treatment outcomes following IV thrombolysis are associated with thrombus density on NCCT. In general, the more dense (higher attenuating) the thrombus, the better the clot seems to respond to IV tPA. ${ }^{14,29}$ Puig et al, ${ }^{29}$ for example, found that patients with lower relative intraclot Hounsfield units had greater resistance to IV tPA. The authors found that a relative Hounsfield unit (the Hounsfield unit of MCA on the symptomatic side/Hounsfield unit of MCA on asymptomatic side) of $<.382$ predicted persistent occlusion after therapy, with a sensitivity and specificity of $100 \%$ and $87 \%$, respectively. Similarly, Kim et al ${ }^{14}$ demonstrated superior recanalization rates of patients treated with $\mathrm{TPA}$ in whom the clot on NCCT demonstrated higher intrathrombus attenuation values.

Similarly, hyperdense clots on NCCT are generally associated with superior outcomes during MT. ${ }^{18,30,31}$ Froehler et $\mathrm{al}^{32}$ for example, reported successful recanalization in $79 \%$ of hyperdense thrombi, but in only $36 \%$ of isodense thrombi. Moftakhar et $\mathrm{al}^{33}$ found superior postintervention TICI grades in patients with higher thrombus density, regardless of intervention type (MT or IV or intra-arterial tPA). Likewise, on MR imaging, the presence of an SVS is predictive of higher rates of recanalization during MT and superior early clinical improvement, compatible with other results of RBC-rich clots. ${ }^{34}$ Although some reports have presented data contradictory to the above findings, these represent a small minority of the current literature. ${ }^{35}$

On CTA, multiple studies have demonstrated that perviousness, based on a greater TAI, predicts better recanalization in patients treated with $\mathrm{tPA} .{ }^{10,36,37}$ Santos et $\mathrm{al}^{10}$ found that patients with pervious clots were more likely to have complete recanalization after tPA therapy compared with a conservatively treated cohort; there was no such significant effect of tPA treatment in patients with impervious thrombi. Mishra et $\mathrm{al}^{36}{ }^{36}$ too, found that pervious clots were 5 times more likely to reperfuse than impervious thrombi. In theory, the superior responsiveness of pervious clots is related to the greater ability of tPA to travel through and thus act on a clot, similar to the blood in which it is administered. The tPA is, therefore, granted greater surface area on which to act; it is, thereby, hypothesized to act with greater efficiency in dissolving a clot. ${ }^{38}$

Multiple studies have also explored the association between clot perviousness on imaging and the degree of success during attempts at MT, which are also detailed in the Online Supplemental Data. Mokin et $\mathrm{al}^{30}$ for example, in examining the results from the Cardiovascular Outcomes for People Using Anticoagulation Strategies (COMPASS) trial, found that perviousness was associated with successful MT attempts. The authors reported that mean perviousness (as defined by the TAI) varied significantly between TICI subgroups: 32.6 for TICI $2 c / 3$ and 17.7 for TICI 0-2a. Santos et $\mathrm{al}^{39}$ reported data from a cohort of patients from the Multicenter Randomized Clinical Trial of Endovascular Treatment of Acute Ischemic Stroke in the Netherlands (MR CLEAN) trial. The authors found that pervious clots (defined as having a TAI of $\geq 10.9$ ) were more likely to both recanalize and have a favorable outcome (mRS $\leq 2$ ).

However, conflicting reports on this topic do exist. Borst et al, ${ }^{40}$ for example, examined a number of thrombus characteristics on both NCCT and CTA: location (dichotomized as involving or not involving the ICA terminus), distance from ICA terminus to the thrombus, thrombus length and volume, density, and TAI. None of the studied clot characteristics on imaging were associated with treatment-effect modifications. Byun et al, ${ }^{41}$ similarly, found no correlation between perviousness on CTA and first-pass revascularization using stent retrievers.

Because recanalization is associated with better clinical outcomes in acute ischemic stroke, it seems implicit that pervious clots lead to more favorable outcomes. Indeed, an association between perviousness and outcome has been established. ${ }^{39}$ In the study of Santos et al, ${ }^{10}$ for example, perviousness was independently associated with superior outcomes after adjusting for recanalization. The aforementioned study using dynamic CTA similarly found perviousness to predict favorable outcome on the basis of a 3-month $\mathrm{mRS}$ of $\leq 2 .{ }^{13}$ Multiple other studies have confirmed superior outcomes based on the 90-day mRS in patients with pervious thrombi (Table). ${ }^{15,42}$

\section{Radiomics}

Radiomics, a subtype of machine learning, has recently been used to correlate clot appearance on imaging to histologic composition and clinical outcomes. Qiu et $\mathrm{al}_{,}{ }^{43}$ for example, found that radiomic features derived from CTA and NCCT were more predictive of early recanalization following IV tPA than any single clot feature, including perviousness. Hofmeister et $\mathrm{al}^{44}$ used radiomic features of clots on NCCT to predict both first-attempt recanalization and the overall number of passages needed to successfully recanalize a lumen. Most interesting, the radiomic features that correlated with recanalization included lower intrathrombus attenuation, in contradiction to the dogma that higher-density clots are more easily treated. The reason for the discrepancy between the study of Hofmeister et $\mathrm{al}^{44}$ and numerous prior 
studies is unknown, and reflects the need for additional investigation into this topic. An in vitro study using clot analogs by Velasco Gonzalez et al, ${ }^{45}$ meanwhile, found that higher attenuation on NCCT was associated with greater composition of RBCs, while lower attenuation corresponded to greater composition of fibrin. Attempts to correlate MR imaging to clot composition with radiomics have remained sparse in comparison with CTA. ${ }^{46}$

\section{Other Imaging Biomarkers}

Perviousness imaging and radiology-pathology correlations represent only small components of the massive field of clot imaging. Numerous other imaging biomarkers of intracranial clots exist, which hold substantial prognostic and therapeutic significance. Although this review is focused mainly on the subject of perviousness, some of these other imaging markers deserve mention, to grasp the scope of the ever-expanding field.

First, there is thrombus length, which can be measured on both CTA and NCCT. ${ }^{47}$ On NCCT, the length of the thrombus is determined by the size of the increased intraclot attenuation when an HMCAS is present. Thin-section images $(\leq 2.5 \mathrm{~mm})$ are required to adequately visualize clots in this manner. ${ }^{48}$ On CTA, thrombus length is measured by the contrast gap, represented by an intra-arterial filling defect. ${ }^{49}$ However, the distal end of the clot is essentially invisible unless pial collaterals permit opacification of the artery past the thrombus, thereby delineating the back end of the clot. Hence, CTA often leads to overestimation of thrombus length. Delayed-phase imaging, either as part of a multiphase CTA or contrast-enhanced CT, may help overcome this deficiency. ${ }^{50}$ Shorter thrombi have more favorable metrics, including better functional outcome and reduced endovascular procedural times. ${ }^{15}$ Similar results have been reported using volumetric measurements of clots on 3D software: Smaller clots have significantly higher rates of recanalization. ${ }^{51}$

Then, there is thrombus location, which is often described on the basis of arterial segment involvement or by the "distance to thrombus" (the length between the ICA terminus and the proximal clot). ${ }^{40}$ In general, patients with more proximal clots tend to fare worse, with poorer recanalization rates and outcomes. ${ }^{52}$ Bhatia et $\mathrm{al}^{53}$ for example, showed that thrombi in the distal ICA had a recanalization rate of $4.4 \%$, while those in the M1 segment of the MCA had a recanalization rate of $32.3 \%$. A meta-analysis by Seners et $\mathrm{al}^{54}$ found that early recanalization was achieved in $52 \%$ of distal MCA clots, compared with $35 \%$ of clots in the proximal MCA and $13 \%$ of clots in the ICA. Such differences are at least, in part, related to the size of clots found in different locations: Larger-volume clots get lodged in the proximal arteries, while smaller clots are able to travel more distally.

The clot burden score is a semiquantitative method of measuring clot severity, which combines features of both size and location. The clot burden scoring system subtracts points on the basis of arterial segment involvement, with greater value placed on the supraclinoid ICA and MCA trunk; lower clot burden scores imply greater clot burden. ${ }^{55}$ This feature can be assessed on both CTA or MR imaging (eg, using T2* sequences). ${ }^{56}$ Not surprisingly, patients with increased clot burden scores (smaller clots) have better outcomes and higher rates of recanalization. ${ }^{57,58}$

\section{Future Directions}

Where, then, do we currently stand in the field of clot perviousness imaging? Like the appearance of a clot on NCCT, the perviousness of a thrombus seems to predict its responsiveness to therapy. While the density of a clot on NCCT seems to also be associated with its histologic composition, a convincing correlation between perviousness and the histology of a clot remains elusive. Still, the better response of pervious clots to tPA does seem to indicate that pervious clots are more porous, allowing medications to better access and thereby act on the internal components of an occlusive thrombus. In short, what we are "seeing" with perviousness may be more related to intrinsic properties that determine therapeutic success-eg, porosity and composition that support MT—and less related to the major cellular makeup of clots.

In addition, there are complex histologic features of clots that could contribute to response or resistance to therapeutic efforts. Recently, clot components, such as NETs and von Willebrand factor, are increasingly thought to play a pivotal role in thrombus formation and stability. NETs, for example, are webs of DNA fibers that are typically used as a defensive mechanism against infectious organisms. ${ }^{59}$ However, NETs have also been firmly implicated in the creation of thromboses: They influence the coagulation cascade, create a scaffold for RBCs, and promote platelet adhesion and aggregation. ${ }^{60,61}$ Not surprisingly, clots with greater composition of NETs exhibit greater resistance to endovascular therapy, with greater procedural times and number of device passes. ${ }^{62}$ Platelet-rich clots have higher levels of both von Willebrand factor and NETs, possibly explaining the resistance of such clots to thrombolytic effort. ${ }^{63,64}$

Targeted therapies for these components are being developed. Recombinant a disintegrin and metalloprotease with thrombospondin type 1 repeats (ADAMTS13) cleaves von Willebrand factor and has been successfully used in mice to decrease infarct volume. ${ }^{65}$ Deoxyribonuclease I has been shown to accelerate clot lysis by acting on intrathrombus NETs. ${ }^{60}$ Eventually, novel therapeutic efforts such as these may be used as part of an increasingly complex arsenal of stroke treatment options.

More broadly, the goal of intracranial clot imaging is to individualize stroke therapy. As treatment options for stroke increase, effort will be needed to optimize recanalization on the basis of the specific imaging characteristics of intracranial thrombi. For example, if tPA were to be found to be associated with a virtually nil recanalization rate for impervious thrombi, one could use this finding as a reason to forgo fibrinolytic therapy and triage directly to endovascular therapy. Moving forward into this realm will require the rapid use of imaging features such as clot density, perviousness, and radiomics to predict the complex histologic composition of clots.

\section{CONCLUSIONS}

Today, the literature seems to support the growing consensus that perviousness is related to successful recanalization with IV tPA and MT. Effort to correlate perviousness with specific histologic compositions, meanwhile, has been relatively unrevealing. As we move into the future, it is likely that perviousness on CTA will be considered a first step in using imaging for clot characterization. Newer techniques, namely, machine learning, will likely 
offer a substantial benefit for establishing etiologic mechanisms, offering prognostication on stroke outcome, and triaging patients with stroke on the basis of presumed responsiveness to various treatment strategies.

Disclosures: David F. Kallmes—UNRELATED: Grants/Grants Pending: Cerenovus, Insera Therapeutics, Comments: preclinical and clinical research*; Stock/Stock Options: Superior Medical Experts; Marblehead Medical, Comments: founder/ owner. Waleed Brinjikji-RELATED: Grant: National Institutes of Health/National Institute of Neurological Disorders and Stroke, Comments: IR01NS105853-01.* *Money paid to the institution.

\section{REFERENCES}

1. Gunning GM, McArdle K, Mirza M, et al. Clot friction variation with fibrin content: implications for resistance to thrombectomy. $J$ Neurointerv Surg 2018;10:34-38 CrossRef Medline

2. Choi MH, Park GH, Lee JS, et al. Erythrocyte fraction within retrieved thrombi contributes to thrombolytic response in acute ischemic stroke. Stroke 2018;49:652-59 CrossRef Medline

3. Tomkins AJ, Schleicher N, Murtha L, et al. Platelet rich clots are resistant to lysis by thrombolytic therapy in a rat model of embolic stroke. Exp Transl Stroke Med 2015;7:2 CrossRef Medline

4. Shin JW, Jeong HS, Kwon H-J, et al. High red blood cell composition in clots is associated with successful recanalization during intra-arterial thrombectomy. PLoS One 2018;13:e197492 CrossRef Medline

5. Patel TR, Fricano S, Waqas M, et al. Increased perviousness on CT for acute ischemic stroke is associated with fibrin/platelet-rich clots. AJNR Am J Neuroradiol 2021;42:57-64 CrossRef Medline

6. Sporns PB, Hanning U, Schwindt W, et al. Ischemic stroke: histological thrombus composition and pre-interventional CT attenuation are associated with intervention time and rate of secondary embolism. Cerebrovasc Dis 2017;44:344-50 CrossRef Medline

7. Weafer FM, Duffy S, Machado I, et al. Characterization of strut indentation during mechanical thrombectomy in acute ischemic stroke clot analogs. J Neurointerv Surg 2019;11:891-97 CrossRef Medline

8. Fitzgerald S, Mereuta OM, Doyle KM, et al. Correlation of imaging and histopathology of thrombi in acute ischemic stroke with etiology and outcome. J Neurosurg Sci 2019;63:292-300 CrossRef Medline

9. Sporns PB, Jeibmann A, Minnerup J, et al. Histological clot composition is associated with preinterventional clot migration in acute stroke patients. Stroke 2019;50:2065-71 CrossRef Medline

10. Santos EM, Dankbaar JW, Treurniet KM, et al. Permeable thrombi are associated with higher intravenous recombinant tissue-type plasminogen activator treatment success in patients with acute ischemic stroke. Stroke 2016;47:2058-65 CrossRef Medline

11. Boodt N, Compagne KC, Dutra BG, et al. Coinvestigators MR CLEAN Registry. Stroke etiology and thrombus computed tomography characteristics in patients with acute ischemic stroke: a MR CLEAN registry substudy. Stroke 2020;51:1727-35 CrossRef Medline

12. Santos EM, d'Esterre CD, Treurniet KM, et al. PRove-IT investigators. Added value of multiphase CTA imaging for thrombus perviousness assessment. Neuroradiology 2018;60:71-79 CrossRef Medline

13. Chen Z, Shi F, Gong X, et al. Thrombus permeability on dynamic CTA predicts good outcome after reperfusion therapy. AJNR Am J Neuroradiol 2018;39:1854-59 CrossRef Medline

14. Kim EY, Heo JH, Lee S-K, et al. Prediction of thrombolytic efficacy in acute ischemic stroke using thin-section noncontrast CT. Neurology 2006;67:1846-48 CrossRef Medline

15. Dutra BG, Tolhuisen ML, Alves HC, et al. MR CLEAN Registry Investigators. Thrombus imaging characteristics and outcomes in acute ischemic stroke patients undergoing endovascular treatment. Stroke 2019;50:2057-64 CrossRef Medline

16. Santos EM, Yoo AJ, Beenen LF, et al. MR CLEAN Investigators. Observer variability of absolute and relative thrombus density measurements in patients with acute ischemic stroke. Neuroradiology 2016;58:133-39 CrossRef Medline

17. Ho J, Nguyen D, Pirastefahr M, et al. Non-enhanced CT maximum intensity projections for the detection of large vessel occlusions. Austin J Cerebrovasc Dis Stroke 2017;4:1068 Medline

18. Brinjikji W, Duffy S, Burrows A, et al. Correlation of imaging and histopathology of thrombi in acute ischemic stroke with etiology and outcome: a systematic review. J Neurointerv Surg 2017;9:529-34 CrossRef Medline

19. Fitzgerald ST, Wang S, Dai D, et al. Platelet-rich clots as identified by Martius Scarlet Blue staining are isodense on NCCT. J Neurointerv Surg 2019;11:1145-49 CrossRef Medline

20. Niesten JM, van der Schaaf IC, van Dam L, et al. Histopathologic composition of cerebral thrombi of acute stroke patients is correlated with stroke subtype and thrombus attenuation. PloS One 2014;9:e88882 CrossRef Medline

21. Maekawa K, Shibata M, Nakajima H, et al. Erythrocyte-rich thrombus is associated with reduced number of maneuvers and procedure time in patients with acute ischemic stroke undergoing mechanical thrombectomy. Cerebrovasc Dis Extra 2018;8:39-49 CrossRef Medline

22. Liebeskind DS, Sanossian N, Yong WH, et al. CT and MRI early vessel signs reflect clot composition in acute stroke. Stroke 2011;42:1237-43 CrossRef Medline

23. Berndt M, Friedrich B, Maegerlein C, et al. Thrombus permeability in admission computed tomographic imaging indicates stroke pathogenesis based on thrombus histology. Stroke 2018;49:2674-82 CrossRef Medline

24. Benson JC, Fitzgerald ST, Kadirvel R, et al. Clot permeability and histopathology: is a clot's perviousness on CT imaging correlated with its histologic composition? J Neurointerv Surg 2020;12:38-42 CrossRef Medline

25. Cines DB, Lebedeva T, Nagaswami C, et al. Clot contraction: compression of erythrocytes into tightly packed polyhedra and redistribution of platelets and fibrin. Blood 2014;123:1596-1603 CrossRef Medline

26. Payabvash S, Benson JC, Taleb S, et al. Susceptible vessel sign: identification of arterial occlusion and clinical implications in acute ischaemic stroke. Clin Radiol 2017;72:116-22 CrossRef Medline

27. Kim SK, Yoon W, Kim TS, et al. Histologic analysis of retrieved clots in acute ischemic stroke: correlation with stroke etiology and gradient-echo MRI. AJNR Am J Neuroradiol 2015;36:1756-62 CrossRef Medline

28. Schellinger PD, Chalela JA, Kang DW, et al. Diagnostic and prognostic value of early MR imaging vessel signs in hyperacute stroke patients imaged $<3$ hours and treated with recombinant tissue plasminogen activator. AJNR Am J Neuroradiol 2005;26:618-24 Medline

29. Puig J, Pedraza S, Demchuk A, et al. Quantification of thrombus Hounsfield units on noncontrast CT predicts stroke subtype and early recanalization after intravenous recombinant tissue plasminogen activator. AJNR Am J Neuroradiol 2012;33:90-96 CrossRef Medline

30. Mokin M, Waqas M, Fifi J, et al. Clot perviousness is associated with first pass success of aspiration thrombectomy in the COMPASS trial. J Neurointerv Surg 2021;13:509-14 CrossRef Medline

31. Mokin M, Morr S, Natarajan SK, et al. Thrombus density predicts successful recanalization with Solitaire stent retriever thrombectomy in acute ischemic stroke. J Neurointerv Surg 2015;7:104- 07 CrossRef Medline

32. Froehler MT, Tateshima S, Duckwiler G, et al. UCLA Stroke Investigators. The hyperdense vessel sign on CT predicts successful recanalization with the Merci device in acute ischemic stroke. $J$ Neurointerv Surg 2013;5:289-93 CrossRef Medline

33. Moftakhar P, English JD, Cooke DL, et al. Density of thrombus on admission CT predicts revascularization efficacy in large vessel occlusion acute ischemic stroke. Stroke 2013;44:243-45 CrossRef Medline 
34. Darcourt J, Withayasuk P, Vukasinovic I, et al. Predictive value of susceptibility vessel sign for arterial recanalization and clinical improvement in ischemic stroke. Stroke 2019;50:512-15 CrossRef Medline

35. Topcuoglu MA, Arsava EM, Kursun O, et al. The utility of middle cerebral artery clot density and burden assessment by noncontrast computed tomography in acute ischemic stroke patients treated with thrombolysis. J Stroke Cerebrovasc Dis 2014;23:e85-91 CrossRef Medline

36. Mishra SM, Dykeman J, Sajobi TT, et al. Early reperfusion rates with IV tPA are determined by CTA clot characteristics. AJNR Am J Neuroradiol 2014;35:2265-72 CrossRef Medline

37. Labiche LA, Malkoff M, Alexandrov AV. Residual flow signals predict complete recanalization in stroke patients treated with TPA. $J$ Neuroimaging 2003;13:28-33 Medline

38. Alexandrov AV, Demchuk AM, Felberg RA, et al. High rate of complete recanalization and dramatic clinical recovery during tPA infusion when continuously monitored with $2-\mathrm{MHz}$ transcranial Doppler monitoring. Stroke 2000;31:610-14 CrossRef Medline

39. Santos EM, Marquering HA, den Blanken MD, et al. MR CLEAN Investigators. Thrombus permeability is associated with improved functional outcome and recanalization in patients with ischemic stroke. Stroke 2016;47:732-41 CrossRef Medline

40. Borst J, Berkhemer OA, Santos EM, et al. MR CLEAN Investigators, Value of thrombus CT characteristics in patients with acute ischemic stroke. AJNR Am J Neuroradiol 2017;38:1758-64 CrossRef Medline

41. Byun JS, Nicholson P, Hilditch CA, et al. Thrombus perviousness is not associated with first-pass revascularization using stent retrievers. Interv Neuroradiol 2019;25:285-90 CrossRef Medline

42. Bilgic AB, Gocmen R, Arsava EM, et al. The effect of clot volume and permeability on response to intravenous tissue plasminogen activator in acute ischemic stroke. J Stroke Cerebrovasc Dis 2020;29:104541 CrossRef Medline

43. Qiu W, Kuang H, Nair J, et al. Radiomics-based intracranial thrombus features on CT and CTA predict recanalization with intravenous alteplase in patients with acute ischemic stroke. AJNR Am J Neuroradiol 2019;40:39-44 CrossRef Medline

44. Hofmeister J, Bernava G, Rosi A, et al. Clot-based radiomics predict a mechanical thrombectomy strategy for successful recanalization in acute ischemic stroke. Stroke 2020;51:2488-94 CrossRef Medline

45. Velasco Gonzalez A, Buerke B, Görlich D, et al. Clot analog attenuation in non-contrast CT predicts histology: an experimental study using machine learning. Transl Stroke Res 2020;11:940-49 CrossRef Medline

46. Chung JW, Kim YC, Cha J, et al. Characterization of clot composition in acute cerebral infarct using machine learning techniques. Ann Clin Transl Neurol 2019;6:739-47 CrossRef Medline

47. Riedel CH, Jensen U, Rohr A, et al. Assessment of thrombus in acute middle cerebral artery occlusion using thin-slice nonenhanced computed tomography reconstructions. Stroke 2010;41:1659-64 CrossRef Medline

48. Miller TS, Brook AL, Riedel CH, et al. Expanding the role of NCCT in acute stroke imaging: thrombus length measurement and its potential impact on current practice. J Neurointerv Surg 2014;6:5-6 CrossRef Medline

49. De Meyer SF, Andersson T, Baxter B, et al. Clot Summit Group. Analyses of thrombi in acute ischemic stroke: a consensus statement on current knowledge and future directions. Int J Stroke 2017;12:606-14 CrossRef Medline

50. Mortimer AM, Little DH, Minhas KS, et al. Thrombus length estimation in acute ischemic stroke: a potential role for delayed contrast enhanced CT. J Neurointerv Surg 2014;6:244-48 CrossRef Medline

51. Yoo J, Baek JH, Park $\mathrm{H}$, et al. Thrombus volume as a predictor of nonrecanalization after intravenous thrombolysis in acute stroke. Stroke 2018;49:2108-15 CrossRef Medline

52. Linfante I, Llinas RH, Selim M, et al. Clinical and vascular outcome in internal carotid artery versus middle cerebral artery occlusions after intravenous tissue plasminogen activator. Stroke 2002;33:2066-71 CrossRef Medline

53. Bhatia $\mathrm{R}$, Hill MD, Shobha $\mathrm{N}$, et al. Low rates of acute recanalization with intravenous recombinant tissue plasminogen activator in ischemic stroke: real-world experience and a call for action. Stroke 2010;41:2254-58 CrossRef Medline

54. Seners P, Turc G, Maïer B, et al. Incidence and predictors of early recanalization after intravenous thrombolysis: a systematic review and meta-analysis. Stroke 2016;47:2409-12 CrossRef Medline

55. Tan IY, Demchuk AM, Hopyan J, et al. CT angiography clot burden score and collateral score: correlation with clinical and radiologic outcomes in acute middle cerebral artery infarct. AJNR Am J Neuroradiol 2009;30:525-31 CrossRef Medline

56. Derraz I, Bourcier R, Soudant M, et al. THRACE Investigators. Does clot burden score on baseline $\mathrm{T} 2^{\star}-\mathrm{MRI}$ impact clinical outcome in acute ischemic stroke treated with mechanical thrombectomy? J Stroke 2019;21:91-100 CrossRef Medline

57. Derraz I, Pou M, Labreuche J, et al. ASTER and the THRACE Trials Investigators. Clot burden score and collateral status and their impact on functional outcome in acute ischemic stroke. AJNR Am J Neuroradiol 2021;42:42-48 CrossRef Medline

58. Li G, Wu G, Qin Z, et al. Prognostic value of clot burden score acute ischemic stroke after reperfusion therapies: a systematic review and meta-analysis. J Stroke Cerebrovasc Dis 2019;28:104293 CrossRef Medline

59. Martinod K, Wagner DD. Thrombosis: tangled up in NETs. Blood 2014;123:2768-76 CrossRef Medline

60. Laridan E, Denorme F, Desender L, et al. Neutrophil extracellular traps in ischemic stroke thrombi. Ann Neurol 2017;82:223-32 CrossRef Medline

61. Fuchs TA, Brill A, Duerschmied D, et al. Extracellular DNA traps promote thrombosis. Proc Natl Acad Sci U S A 2010;107:15880-85 CrossRef Medline

62. Ducroux C, Di Meglio L, Loyau S, et al. Thrombus neutrophil extracellular traps content impair tPA-induced thrombolysis in acute ischemic stroke. Stroke 2018;49:754-57 CrossRef Medline

63. Staessens S, Denorme F, Francois O, et al. Structural analysis of ischemic stroke thrombi: histological indications for therapy resistance. Haematologica 2020;105:498-507 CrossRef Medline

64. Douglas A, Fitzgerald S, Mereuta OM, et al. Platelet-rich emboli are associated with von Willebrand factor levels and have poorer revascularization outcomes. J Neurointerv Surg 2020;12:557-62 CrossRef Medline

65. Bongers $\mathrm{TN}$, de Maat MP, van Goor $\mathrm{ML}$, et al. High von Willebrand factor levels increase the risk of first ischemic stroke: influence of ADAMTS13, inflammation, and genetic variability. Stroke 2006;37:2672-77 CrossRef Medline 